\title{
Communication Strategies Used to Obtain Clinical Histories Before Remotely Prescribing Antibiotics for Postal Treatment of Uncomplicated Genital Chlamydia: Service Evaluation
}

Hannah McCulloch $^{1}$, MSc; Jonathan Syred ${ }^{1}$, MSc; Gillian Holdsworth ${ }^{2}$, MSc, MPH, MBChB, FFPH; Chris Howroyd ${ }^{2}$, BSc, MPhil; Elena Ardines ${ }^{2}$, BSc; Paula Baraitser ${ }^{1,2,3}$, BSc, MSc, MBBS, MD, MA, FFPH, FFSRH

\author{
${ }^{1}$ School of Population Health \& Environmental Sciences, King's College London, London, United Kingdom \\ ${ }^{2} \mathrm{SH}: 24$, London, United Kingdom \\ ${ }^{3}$ Department of Sexual Health and HIV, King's College Hospital, London, United Kingdom
}

\section{Corresponding Author:}

Paula Baraitser, BSc, MSc, MBBS, MD, MA, FFPH, FFSRH

School of Population Health \& Environmental Sciences

King's College London

Weston Education Centre, 10 Cutcombe Rd

Denmark Hill Campus, SE5 9RJ

London

United Kingdom

Phone: 4407525630865

Email: paula baraitser@mac.com

\section{Abstract}

Background: Web-based services for testing of sexually transmitted infections are widely available across the United Kingdom. Remote prescriptions with medications posted home may support prompt treatment; however, the absence of face-to-face contact with clinicians raises clinical safety issues as medical history may not be accurately provided.

Objective: This service evaluation aimed to capture the use and explore the safety of 3 remote communication strategies employed within a web-based service offering remote prescriptions of antibiotics, delivered via post, for uncomplicated genital Chlamydia trachomatis. User acceptability and time-from-diagnosis-to-treatment were also obtained.

Methods: Three iterations of the service were compared, where medical history was collected via SMS text message, telephone, or a secure web form before a prescription was issued. We contacted users after they were issued a prescription and completed the medical history a second time via telephone, asking when they took their medication and how they felt about the service. The primary safety measure was agreement in information supplied at 2 assessments (ie, clinical and evaluation assessment) on key elements of safe prescribing: allergies, current medications, or contraindicating clinical conditions or symptoms. Agreement in information between clinical and evaluation assessment was summarized as a binary variable. Factors associated with the assessment agreement variable were explored using univariate and multivariate analysis. The secondary evaluation measures were recall of and adherence to instructions for taking medication, time-from-diagnosis-to-treatment, and acceptability of the web-based service.

Results: All web-based service users, resident in the London Boroughs of Lambeth and Southwark with a positive chlamydia diagnosis, who were eligible for and chose postal treatment between February 15, 2017, and October 24, 2017, were invited to participate in this service evaluation. Of 321 eligible users, 62.0\% (199) participated. A total of 27.6\% (55/199) users completed the clinical assessment via SMS text message, 40.7\% (81/199) users via telephone, and 31.7\% (63/199) users via a secure web form. Those who were assessed for prescription via SMS text message were less likely to have an agreement in safe prescribing information than those assessed via telephone (adjusted odds ratio [aOR] 0.22, 95\% CI 0.08-0.61; $P=.004$ ). We found no statistically significant difference in odds of agreement between the web form and telephone assessment (aOR 0.50, 95\% CI 0.17-1.43; $P=.20$ ). Median time-to-treatment was 4 days (IQR 3-5.5). In addition, 99.0\% (196/199) of users reported understanding remote communication, and $89.9 \%$ (178/198) would use the service again.

Conclusions: Postal treatment is an acceptable and rapid treatment option for uncomplicated genital chlamydia. Clinical assessment via SMS text message before remote prescription may not be accurate or sufficient. As health care is delivered via 
the web, strategies that support safe remote prescribing are increasingly important, as is their evaluation, which should be robust and carefully considered.

(J Med Internet Res 2020;22(6):e15970) doi: 10.2196/15970

\section{KEYWORDS}

sexual health; electronic prescribing; telemedicine; remote consultation; sexually transmitted diseases, bacterial

\section{Introduction}

\section{Background}

Web-based services for testing for sexually transmitted infections (STI) with test kits sent home are widely implemented in the United Kingdom [1,2]. In these services, users order a test kit from a web-based service, take the samples themselves, and post them to a laboratory with results given via SMS text message or telephone. There is evidence that they increase testing uptake in comparison with clinic-based services [3], but the clinical and public health impact of better access to testing requires prompt treatment of the diagnosed infections to prevent onward transmission. Remote prescriptions with medication posted home may facilitate prompt treatment.

Remote prescriptions without face-to-face health professional contact raise safety concerns [4]. The UK General Medical Council advises that clinicians should be satisfied in their ability to adequately assess the patient's condition through satisfactory medical and drug history, including allergies before remote prescribing, and recommends consideration of the limitations of the medium of communication used to ascertain this information [5]. Health Care Improvement Scotland and the UK National Prescribing Centre have made similar recommendations $[4,6,7]$, advocating a cautious approach to remote prescribing. This is particularly important when prescribing treatment for chlamydia within a web-based sexual health service because (1) there is no face-to-face contact throughout the process of testing, diagnosis, and treatment; (2) sexual health service records are not linked to the primary care record making it difficult to cross-check information, and (3) instructions for use and partner notification are provided remotely.

In this context, it is therefore, particularly important that there is effective remote communication to obtain accurate and sufficient medical history for prescribing, and to ensure correct use of medication and partner notification.

Research has documented poor practice in remote prescribing with medications available without a prescription or an appropriate medical history [8,9]; there are obvious health risks associated with this poor practice $[10,11]$. However, remote prescribing is also delivered by highly regulated providers where doctors obtain clinical histories through telephone, video, or email consultations [12,13]. There is good evidence that self-completed digital forms collect reliable data on past medical histories for diagnosis [14-17], but little evidence on their value before prescribing. As many health systems move toward a digital first approach (see, eg, the National Health Service, NHS long-term plan [18]) and increasingly use digital or web-based forms for clinical histories, we predict a need to understand their ability to generate accurate information for prescribing.

We developed and piloted remote prescribing and postal treatment of uncomplicated chlamydia infection within a web-based sexual health service. The process and outcomes of testing have been described elsewhere [3,19]. This service was evaluated during its implementation and development to monitor its clinical safety. As the service evolved, 3 remote communication strategies were used to take clinical histories before the prescribing and postal delivery of treatment of uncomplicated chlamydia. As the service evolved, the accuracy of the information obtained through each remote communication strategy was checked by telephoning users after they had received their prescriptions to recheck the information that they had provided. We sought to understand the safety issues highlighted by this service improvement activity. To do this, we described 3 cycles of service development to understand:

- How different media of assessment support accurate medical histories for prescribing

- To what extent service users understood remotely delivered instructions for use

- How different strategies for remote prescription and treatment impacted on time-to-treatment

\section{The Service Evaluated}

Sexual Health 24 hours a day (SH:24) is an NHS commissioned web-based service that specializes in system transformation in sexual health services through agile and design-led thinking, using an iterative process of build/test/learn for innovation. $\mathrm{SH}$ :24 offers postal self-sampling test kits for chlamydia, gonorrhea, HIV, and syphilis. Test kits are ordered through a website, with those reporting symptoms of infection referred to local clinics. Test kits are sent by post in discreet packaging that includes the materials for self-sampling-urine for men and vaginal samples for women-and a finger-prick blood sample for HIV and syphilis. The user posts the samples to a laboratory for testing. Chlamydia, gonorrhea, syphilis, and negative HIV test results are delivered via SMS text message. Reactive HIV test results are delivered via telephone with referral to local clinics for confirmatory testing.

Those with positive chlamydia results who are older than 18 years and asymptomatic are offered postal chlamydia treatment and complete a remote assessment to check their eligibility for the appropriate antibiotic. If eligible, an electronic prescription is issued by a clinician, and the medication is dispensed, packaged, and dispatched by a regulated pharmacy through the Royal Mail registered (but not signed for) postal service. If ineligible for the treatment offered by the web-based service, which at the time of evaluation was a single $1 \mathrm{~g}$ dose of 
Azithromycin (SDA) users would be directed to local clinic services for treatment.

During and in response to the evaluation, the media of communication for assessment before the remote prescription changed 3 times.

1. During the first iteration of the service, eligibility was assessed via SMS text message. A single message rather than multiple messages was used as a break in communication during a process (eg, a loss of phone connection) would disrupt the assessment process. The message stated the following:

Your chlamydia result is positive. We would like to post you a single dose treatment. You would receive it the next working day. First, we need to know: Are you taking medicines or allergic to any medicines, soya or peanuts? (this is important because the medicine may trigger your allergy or interact with other medicines). Do you have liver, kidney, heart problems, or myasthenia gravis? (this is important because treatment may worsen your condition). Are you pregnant or breastfeeding? (this is important as the treatment may affect your baby). Do you have any symptoms: fever, joint pain, pelvic (lower abdominal) pain, or anal pain? (this is important as you may need a different treatment). If you answered no to ALL of these questions, reply NO. If you answered yes to ANY of these questions, reply YES. If you would like to go to a clinic for treatment instead, please reply CLINIC. Text back if you would like help. Thanks, SH:24.

Those that responded no were then sent this message.

Thank you. Your treatment is now being prepared. You have told us that you are not taking any medicines, you do not have any medical problems (liver, kidney, heart, myasthenia gravis) and you do not have any symptoms of chlamydia. Text back if you have any queries or questions we always prefer to answer queries to prevent any future problems. Thanks, SH:24

2. During the second iteration, the same questions were asked by a clinician over the telephone with responses recorded in the web-based clinical record.

3. During the third iteration, the same questions were asked via a secure web form, which was self-completed by service users.

Instructions for medication use, including abstinence from sexual intercourse for 7 days after commencing treatment and partner notification was provided in written form with the medication. The change from iteration 1 to iteration 2 occurred because a user reported an allergy in the evaluation that was not reported in the clinical assessment. The change from iteration 2 to iteration 3 occurred because it was felt to be time inefficient for the clinical team. Iteration 3 is the system currently implemented.

\section{Methods}

\section{Design and Data Collection}

All SH:24 users, resident in the London Boroughs of Lambeth and Southwark, with a positive chlamydia diagnosis who were eligible for and chose postal treatment between February 15, 2017, and October 24, 2017, were invited to take part in this service evaluation. Data were collected through a standardized telephone questionnaire delivered by a trained researcher after the medication had been prescribed and dispatched. This questionnaire documented relevant medical history, medication history (including allergies), time-to-treatment, and user experience. The full questionnaire can be found in Multimedia Appendix 1.

Each user, in effect, received the medical eligibility questions twice-once during their clinical assessment and once during the service evaluation. In iterations 1 and 3 , there was a difference in the mode of communication between the clinical assessment and the evaluation assessment. During iteration 2, the mode of questioning before and after treatment delivery was the same. This is illustrated in Figure 1. As this was a service evaluation, there were no power calculations to determine the number of people in each arm. The service developed in response to real-time analysis of the evaluation rather than according to a research plan.

\section{Measures}

We refer to the preprescription assessment as the clinical assessment and the postprescription assessment as the evaluation assessment. The primary safety measure was agreement in information supplied at the 2 assessments on key elements of safe prescribing: allergies, current medications, or contraindicating clinical conditions or symptoms. The secondary evaluation measures were recall of and adherence to instructions for taking the medication, time-from-diagnosis-to-treatment, and acceptability of the postal treatment service.

\section{Analysis}

Descriptive statistics were used to summarize participant characteristics using parametric and, where appropriate, nonparametric tests. Agreement in key safe prescribing information supplied at the clinical assessment and the evaluation assessment was summarized as 1 binary variable, where matching information between assessments was given a value of 1 , and conflicting or disparate information was given a value of 0 . Logistic regression was then used to determine factors associated with agreement in key safe prescribing information. Univariate analysis was used to determine its relationship with demographic characteristics, previous clinic attendance, and method of clinical assessment, and variables significant at a 0.05 level were compiled to create a multivariable logistic model. A Kruskal-Wallis $\mathrm{H}$ test was conducted to determine the relationship between median time-to-treatment and method of clinical assessment. 
Figure 1. Data collection points and methods.

\begin{tabular}{|l|l|l|}
\hline \multicolumn{1}{|c|}{ Clinical assessment } & \multirow{2}{*}{} & \multicolumn{1}{|c|}{ Evaluation assessment } \\
\cline { 1 - 1 } Iteration $1-$ via SMS & \multirow{2}{*}{ Postal treatment } & Assessment via telephone \\
Iteration $2-$ via telephone & & Assessment via telephone \\
Iteration $3-$ via online form & & Assessment via telephone \\
\hline
\end{tabular}

\section{Ethical Considerations}

This work observed a build-test-learn cycle based on a human-centred design approach to service development carried out by a digital sexual health service, which adapted strategies that are already used by UK-registered web-based pharmacies. As a service evaluation, it focuses on auditable outcomes such as compliance with medical advice and processes, as well as time to treatment. For this service evaluation project, we did not request a formal ethics review; however, we conducted the evaluation in line with standard ethical procedures. To maintain confidentiality, users were asked to confirm the first line of their address before any information was disclosed about the nature of the telephone call. They were given full information about the evaluation and given the option to participate. Paper surveys, filled in by the researcher while on the phone, were marked with the user's unique identifier and stored in a locked filing cabinet. Unique identifiers could only be linked to identifiable data by accessing the web-based service.

\section{Results}

\section{Evaluation Uptake}

During the study period, there were 581 chlamydia diagnoses and offers of postal treatment, of which 260 (44.8\%) chose to access or were directed to clinic-based services (mainly because they had symptoms). Of the 321 who chose postal treatment, $199(62.0 \%)$ participated in the evaluation (101 could not be contacted, 16 declined to participate, and 5 were excluded-3 repeat users, 1 could not confirm their address, and 1 had decided to attend a clinic). Of the 199 participants, 55 (27.6\%) completed the clinical assessment via SMS text message, 81 $(40.7 \%)$ via telephone, and $63(31.7 \%)$ via a secure web form (Figure 2). The median time between the clinical assessment and the evaluation assessment was 17 days (IQR 10-35).

Figure 2. Evaluation flowchart.

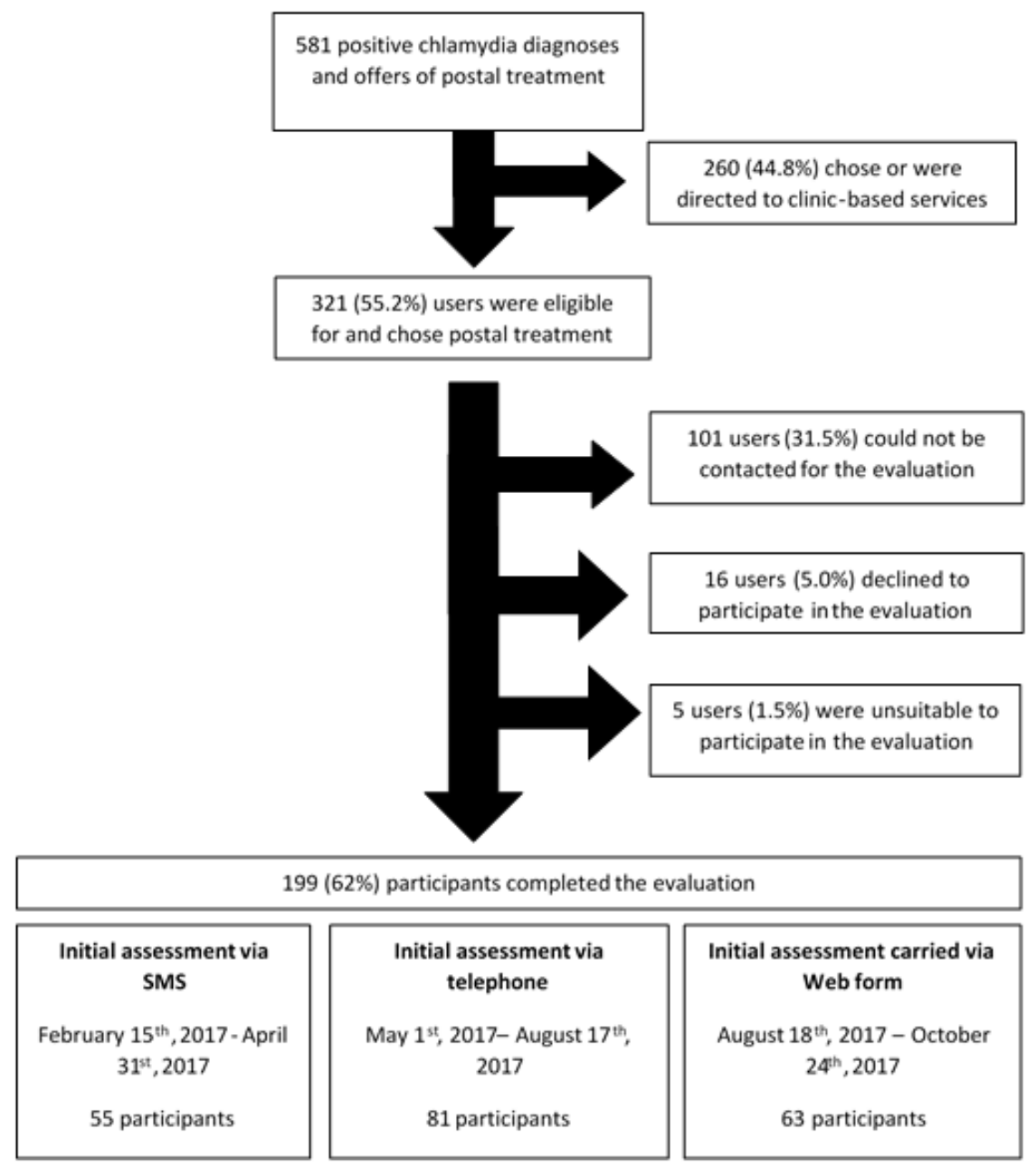




\section{Participant Characteristics}

The sociodemographic and clinic attendance characteristics of those who did and did not take part in the evaluation are described in Table 1.

Table 1. Sociodemographic characteristics of individuals who ordered postal treatment for chlamydia $(\mathrm{N}=321)$.

\begin{tabular}{|c|c|c|}
\hline Sociodemographic characteristic & Sample $(\mathrm{n}=199), \mathrm{n}(\%)$ & Population $(\mathrm{N}=321), \mathrm{n}(\%)$ \\
\hline \multicolumn{3}{|l|}{ Age group (years) } \\
\hline $18-19$ & $21(10.6)$ & $37(11.5)$ \\
\hline $20-24$ & $83(41.7)$ & $126(39.3)$ \\
\hline $25-29$ & $54(27.1)$ & $95(29.6)$ \\
\hline $30-34$ & $26(13.1)$ & $39(12.1)$ \\
\hline $35+$ & $15(7.5)$ & $24(7.5)$ \\
\hline \multicolumn{3}{|l|}{ Gender } \\
\hline Male & $99(49.7)$ & $168(52.3)$ \\
\hline Female & $100(50.3)$ & $153(47.7)$ \\
\hline \multicolumn{3}{|l|}{ Ethnicity } \\
\hline White & $76(38.2)$ & $143(44.6)$ \\
\hline Black British or Black Caribbean or Black African & $73(36.7)$ & $103(32.1)$ \\
\hline Asian or Asian British & $8(4.0)$ & $12(3.7)$ \\
\hline Mixed or multiple groups & $24(12.1)$ & $38(11.8)$ \\
\hline Other or prefer not to say & $18(9.0)$ & $25(7.8)$ \\
\hline \multicolumn{3}{|l|}{ Sexual orientation } \\
\hline Heterosexual & $176(88.5)$ & $288(89.7)$ \\
\hline Homosexual & $5(2.5)$ & $7(2.2)$ \\
\hline Bisexual & $14(7.0)$ & $17(5.3)$ \\
\hline Prefer not to say & $4(2.0)$ & 9. $(2.8)$ \\
\hline \multicolumn{3}{|l|}{ Index of multiple deprivation quintile } \\
\hline 1 (most deprived) & $66(33.2)$ & $108(33.6)$ \\
\hline 2 & $83(41.7)$ & $127(39.6)$ \\
\hline 3 & $32(16.1)$ & $56(17.5)$ \\
\hline 4 & $13(6.5)$ & $19(5.9)$ \\
\hline 5 (least deprived) & $5(2.5)$ & $11(3.4)$ \\
\hline \multicolumn{3}{|l|}{ Ever attended a sexual health clinic? } \\
\hline Yes & $147(73.9)$ & $227(70.7)$ \\
\hline No & $52(26.1)$ & $94(29.3)$ \\
\hline \multicolumn{3}{|l|}{ Attended a sexual health clinic in the last 12 months? ${ }^{a}$} \\
\hline Yes & $77(38.7)$ & $109(34.0)$ \\
\hline No & $94(47.2)$ & $150(46.7)$ \\
\hline Did not answer & $28(14.1)$ & $62(19.3)$ \\
\hline
\end{tabular}

${ }^{\mathrm{a}}$ Was not answered by all participants.

\section{Agreement in Key Safe Prescribing Information}

We considered all discrepancies between the clinical and evaluation assessment. New clinical information reported at the evaluation assessment but not the clinical assessment was reported to the web-based service clinical team who managed it according to the clinical incident policy.

During the clinical assessment, 154 participants reported no contraindications, and all except 2 reported the same information at the evaluation assessment. The 2 exceptions were 2 women who were taking the contraceptive pill. 
During the evaluation assessment, 45 individuals reported potential contraindications, and 31 of these omitted this from their clinical assessment (14 unreported medications, 6 allergies, 1 previous operation, and 10 genital symptoms). One of these contraindications, an allergy to peanuts, could have caused a serious interaction with the medication prescribed.

Of the 33 discrepancies between clinical and evaluation assessments, 15 (46\%) occurred when the clinical assessment was completed via SMS text message, $8(24 \%)$ via telephone, and $10(30 \%)$ via the secure web form. Univariate analysis showed that method of clinical assessment, gender, and sexuality were independently associated with agreement between the clinical and evaluation assessment. When combined in a multivariable model, method of initial assessment, gender, and sexuality remained statistically significantly associated with agreement between the 2 assessments.

The adjusted odds of agreement between assessments were $78 \%$ less among participants who completed their clinical assessment via SMS text messaging compared with those who completed this via telephone. This result was statistically significant (see Table 2). We found no statistically significant difference between the odds of agreement between assessments completed via telephone and via the secure web form.

Of those who took their medication, $91.1 \%$ (175/192) correctly recalled advice to abstain from sex for 7 days after they and their partner had commenced treatment, 93.4\% (184/197) recalled advice on partner notification, and $89.3 \%$ (176/197) had notified partners. 
Table 2. Crude and adjusted odd ratios of agreement in reporting information.

\begin{tabular}{|c|c|c|c|c|}
\hline Exposure variable & Crude odds ratio $(95 \% \mathrm{CI})$ & $P$ value & Adjusted odds ratio $(95 \% \mathrm{CI})^{\mathrm{a}}$ & $P$ value \\
\hline \multicolumn{5}{|l|}{ Method of initial assessment } \\
\hline Call & 1 (reference $^{\mathrm{b}}$ ) & $-^{\mathrm{b}}$ & 1 (reference) & $-^{\mathrm{b}}$ \\
\hline SMS text message & $0.29(0.11-0.75)$ & .01 & $0.22(0.08-0.61)$ & .004 \\
\hline Secure web form & $0.58(0.21-1.57)$ & .28 & $0.50(0.17-1.43)$ & .20 \\
\hline \multicolumn{5}{|l|}{ Ever attended a clinic? } \\
\hline Yes & 1 (reference) & $-\mathrm{b}$ & 1 (reference) & $-\mathrm{b}$ \\
\hline No & $2.21(0.81-6.07)$ & .12 & ${ }_{-}^{\mathrm{d}}$ & $-\mathrm{d}$ \\
\hline \multicolumn{5}{|l|}{ Gender } \\
\hline Female & 1 (reference) & $-\mathrm{b}$ & 1 (reference) & $-\mathrm{b}$ \\
\hline Male & $2.66(1.19-5.93)$ & .02 & $2.75(1.16-6.56)$ & .02 \\
\hline \multicolumn{5}{|l|}{ Age (years) } \\
\hline $18-19$ & 1 (reference) & $-\mathrm{b}$ & 1 (reference) & $-\mathrm{b}$ \\
\hline $20-24$ & $1.68(0.52-5.40)$ & .38 & $-{ }^{\mathrm{d}}$ & $-^{\mathrm{d}}$ \\
\hline $25-29$ & $2.10(0.58-7.55)$ & .26 & ${ }_{-}^{\mathrm{d}}$ & $\perp^{\mathrm{d}}$ \\
\hline $30-34$ & $1.31(0.32-5.32)$ & .70 & $-^{\mathrm{d}}$ & ${ }_{-}^{\mathrm{d}}$ \\
\hline $35+$ & $1.25(0.25-6.29)$ & .78 & $-^{d}$ & $-^{d}$ \\
\hline \multicolumn{5}{|l|}{ Ethnicity } \\
\hline White & 1 (reference) & $-\mathrm{b}$ & 1 (reference) & ${ }^{\mathrm{b}}$ \\
\hline Black British/Caribbean/African & $0.87(0.37-2.05)$ & .74 & $\ldots \mathrm{d}$ & - d \\
\hline Asian/Asian British & $1.31(0.15-11.66)$ & .81 & ${ }^{\mathrm{d}}$ & ${ }^{\mathrm{d}}$ \\
\hline Mixed/multiple groups & $0.56(0.19-1.71)$ & .31 & $-^{\mathrm{d}}$ & $-^{\mathrm{d}}$ \\
\hline Other/prefer not to say & $3.19(0.39-26.26)$ & .28 & $-^{\mathrm{d}}$ & $\perp^{\mathrm{d}}$ \\
\hline \multicolumn{5}{|l|}{ Sexuality } \\
\hline Heterosexual & 1 (reference) & $-\mathrm{b}$ & 1 (reference) & $-\mathrm{b}$ \\
\hline Homosexual & $0.69(0.07-6.45)$ & .75 & $0.34(0.03-3.65)$ & .37 \\
\hline Bisexual & $0.23(0.07-0.72)$ & .01 & $0.19(0.06-0.66)$ & .009 \\
\hline Prefer not to say & $-^{c}$ & $-^{c}$ & $-^{\mathrm{c}}$ & $\underline{-}^{c}$ \\
\hline \multicolumn{5}{|l|}{ Index of multiple deprivation q uintile } \\
\hline 1 (most deprived) & 1 (reference) & ${ }^{\mathrm{b}}$ & 1 (reference) & $-^{b}$ \\
\hline 2 & $1.10(0.47-2.56)$ & .83 & $-^{\mathrm{d}}$ & $-{ }^{\mathrm{d}}$ \\
\hline 3 & $3.33(0.70-15.90)$ & .13 & $-{ }^{\mathrm{d}}$ & $\underline{\mathrm{d}}^{\mathrm{C}}$ \\
\hline 4 & $0.36(0.10-1.28)$ & .13 & $-{ }^{\mathrm{d}}$ & $-\mathrm{d}$ \\
\hline 5 (least deprived) & $-^{\mathrm{c}}$ & $-^{c}$ & ${ }^{\mathrm{d}}$ & $-{ }^{\mathrm{d}}$ \\
\hline
\end{tabular}

${ }^{\mathrm{a}}$ Only variables where crude odds ratios were found to be significant $(P<.05)$ were carried into the multivariable model.

${ }^{b}$ Reference group.

${ }^{\mathrm{c}}$ Not applicable, as variable was not carried into the multivariable model.

${ }^{\mathrm{d}}$ Not applicable, as no sample participants within these categories. 


\section{Time-From-Diagnosis-to-Treatment}

From the 192 participants who took their treatment, median time-to-treatment was 4 days (IQR 3-5.5). A total of $91.7 \%$ $(176 / 192)$ of those evaluated were treated within 7 days of receiving their positive diagnosis.

A Kruskal-Wallis $\mathrm{H}$ test was used to analyze the relationship between time-to-treatment and the medium of the clinical assessment as this variable was not normally distributed. Of the 192, 55 were assessed via SMS text message, 76 via telephone, and 61 via web form. There was a statistically significant difference between time-to-treatment by method of clinical assessment $\quad\left(H_{2}=24.169 ; \quad P<.001\right)$ with a median time-to-treatment of 2.5 days for SMS text messaging, 4 days for web form, and 4.5 days for telephone call. Similarly, statistically significant differences were found between SMS text message and telephone call $\left(H_{2}=21.990 ; P<.001\right)$ and SMS text message and web form $\left(H_{2}=14.702 ; P<.001\right)$. There was no statistically significant difference in the median time-to-treatment between web form and telephone call.

\section{User Acceptability}

The majority of users $(185 / 197,93.9 \%)$ were happy with the information provided on treatment. Almost all users reported that they could both understand $(196 / 199,99.0 \%)$ and were comfortable $(196 / 198,98.5 .0 \%)$ with the SMS text messages they received from the service. $19.4 \%$ (38/196) contacted SH:24 for support, and $89.9 \%(178 / 198)$ said they would use the web-based service again.

\section{Discussion}

\section{Principal Findings}

This service evaluation documented an iterative process of testing 3 methods of clinical assessment before remote prescribing. It showed that users are significantly more likely to report accurate clinical histories during a telephone consultation than through a single SMS text message. We did not find a statistically significant difference between the accuracy of clinical histories reported via telephone and via the secure web form. It showed that treatment via a web-based sexual health service in general, and SMS text message assessment in particular, supports rapid treatment that is well within the standards set in current guidance; the National Chlamydia Screening Programme (NCSP) audit standard aims for $95 \%$ of patients to have a time-to-treatment of 6 weeks or less [20,21]. An NCSP audit of chlamydia treatment services carried out in 2017 [22] found that $92.0 \%$ of the sample met this standard, whereas within this service evaluation, $91.7 \%$ $(176 / 192)$ of those evaluated were treated within 7 days of receiving their positive diagnosis. This is comparable with findings from Estcourt et al's [23] exploratory studies into an electronic sexual health clinic system for management, prevention, and control of STIs, where results were delivered via a secure web portal and treatment was collected from a local pharmacy.

Our findings are important as treatment is increasingly part of routine web-based sexual health services. This is reflected both in the use of the web-based service evaluated here and quality standards and guidelines recently released by relevant professional bodies.

Since the start of the service in 2017,5130 chlamydia treatments have been delivered via SH:24 by post in 14 different areas of the country. Postal treatment is highly acceptable to service users, with $80 \%$ of those offered treatment by post taking up this offer. More information about the uptake and number of orders can be found in Multimedia Appendix 2. The service now uses the secure web form to assess eligibility, and SMS text messaging or telephone are no longer used, except to gain more detail on contraindications that have been reported in the form.

Since the development of the service, the Faculty of Sexual and Reproductive Healthcare and the British Association for Sexual Health and HIV (BASHH) have published the first quality standards for online and remote providers of sexual and reproductive health care [24]. These standards not only reiterate the General Medical Council's (GMC's) recommendations on safety and remote prescribing [5] but also highlight the safety nets services should have to navigate and mitigate risks that may come with remote consultations [24]. The service evaluated here has developed a 2-way process around the secure web form that is now used as the clinical assessment for eligibility in the web-based remote chlamydia treatment service where free textboxes within the web form allow users to share, for example, any medication they may be taking. Furthermore, as per the GMC guidelines, they now ask patients for their consent to share treatment information with their general practitioner [25].

Other changes in the service since this evaluation reflect updated clinical guidelines; during the evaluation users were offered SDA as first-line treatment; however, in response to BASHH recommendations [21], the first-line treatment offer for uncomplicated urogenital, pharyngeal, and rectal chlamydia infections is now Doxycycline $100 \mathrm{mg}$ bd for 7 days.

\section{Interpretation}

Higher risks associated with the SMS text message assessment provide important learning. New technologies such as crossplatform messaging services (eg, WhatsApp) are increasingly used by businesses for secure communication with their customers and strategies for assessment before medical prescribing may develop in this direction. We recommend further investigation into the risks and benefits of these approaches. The SMS text messaging strategy used here was limited to a single (rather long) message that included multiple questions and required a single answer. This is suboptimal and is a function of the limitations of SMS text messaging technology. It was not possible to break up the message into individual SMS text messages in case the connection was lost halfway through the interaction. SMS text messages remain undelivered when the connection breaks, unlike, for example, WhatsApp, where messages are delivered as soon as the connection is resumed. web forms are commonly used for history taking before prescriptions. This evaluation suggests that this is a promising approach, but our sample size was insufficient to provide significant results, and future research 
should explore their performance in comparison with telephone and face-to-face assessment.

Our analysis assumes that telephone assessment by an experienced clinician is safe as this is standard practice, but it also suggests that even this method is associated with inaccuracies. Even face-to-face consultations are associated with medication errors (usually prescribing errors) in hospitals varying between $2 \%$ and $14 \%$ [26]. It is likely that no method is consistently reliable in obtaining an accurate history. Situations where the clinical history can be checked against previous health records have obvious advantages, but this is not possible in sexual health where information traditionally is not linked to the rest of the medical record as a strategy to maintain confidentiality [27].

\section{Limitations}

A small evaluation of a rapidly evolving service, this service evaluation did not calculate sample size when conceived. Participants were not allocated to a method of clinical assessment; designed to judge current care provided, the service evaluation followed an evolving service, where 3 iterations of the service design allowed for retrospective exploration of factors associated with agreement in safe prescribing information, including method of clinical assessment. Although, even with a small sample, we did find a difference in odds of agreement between SMS text messaging and telephone call, a robust, considered piece of research, with a calculated sample size, would be needed to fully explore the relationship between method of clinical assessment and agreement in safe prescribing information. As methods were tested consecutively, users were not randomly allocated to a particular method. Hence, those carrying out the follow-up assessment may not have been blinded; a possible source of bias.
We recognize the role that reporting bias may have played in user evaluation assessments. Users asked to reflect on their symptoms, once they have been given a diagnosis, may recognize symptoms they previously may have been deemed unrelated. Several women reported abdominal pain in the evaluation assessment, that they had considered period pain before they received their positive diagnosis. Preexisting literature highlights poor knowledge of nature and symptoms of chlamydia infection [28-30]. In a study of 18- to 24-year olds, a third of respondents were unaware of the asymptomatic nature of chlamydia infection, and $80.2 \%$ of respondents failed to recognize lower abdominal pain as a potential symptom in women [30].

Although most participants of this service evaluation stated a preference for a remote treatment service, as the sample consists solely of those who self-identify as asymptomatic, this should not be generalized to everyone seeking treatment. Sexual health clinics remain an integral element of STI treatment and care, and web-based services should be well integrated with face-to-face services [31,32]. However, considering that at least $70 \%$ of women and $50 \%$ of men infected with chlamydia are asymptomatic [33,34], this shows acceptability in a large proportion of those who need treatment.

\section{Conclusions and Recommendations}

Postal treatment is an acceptable and rapid treatment option for uncomplicated genital chlamydia. Clinical assessment via SMS text message before remote prescription may not be accurate or sufficient. As health care is delivered, strategies that support safe remote prescribing are increasingly important, as is their evaluation, which should be robust and carefully considered.

\section{Acknowledgments}

This service evaluation was undertaken as part of a multidisciplinary evaluation of web-based sexual health services funded by Guys and St Thomas' Charity.

\section{Authors' Contributions}

PB, JS, GH, and CH contributed to the study conception. AS, JS, PW, and HM were responsible for data collection. HM contributed to the analysis. HM and PB contributed to the write-up.

\section{Conflicts of Interest}

$\mathrm{PB}, \mathrm{GH}$, and $\mathrm{CH}$ are directors of SH:24 (a not-for-profit community interest company). EA is also employed by SH:24. Since October 2019, HM has been working as a research associate at SH:24.

\section{Multimedia Appendix 1}

Service evaluation questions. [DOCX File, 13 KB-Multimedia Appendix 1]

\section{Multimedia Appendix 2}

Information on chlamydia treatment service provision. [DOCX File, 13 KB-Multimedia Appendix 2]

\section{References}


1. Cleary M, O'Sullivan J. P145 London sexual health transformation programme. Sex Transm Infect 2017;93:A64-A65 [FREE Full text] [doi: 10.26226/morressier.58ef94ddd462b80290b50420]

2. NHS England. 2019. Find Chlamydia - Free Online Tests for u-25s Services URL: https://www.nhs.uk/Service-Search/ Chlamydia-free-online-tests-for-u-25s/LocationSearch/344 [accessed 2019-01-25]

3. Wilson E, Free C, Morris TP, Syred J, Ahamed I, Menon-Johansson AS, et al. Internet-accessed sexually transmitted infection (e-STI) testing and results service: A randomised, single-blind, controlled trial. PLoS Med 2017 Dec;14(12):e1002479 [FREE Full text] [doi: 10.1371/journal.pmed.1002479] [Medline: 29281628]

4. Healthcare Improvement Scotland. 2014 Apr 15. Implementing an Electronic Prescribing and Medicines Administration System: A Good Practice Guide URL: http://www.healthcareimprovementscotland.org/our work/technologies and medicines/ electronic_prescribing/good_practice_guide.aspx [accessed 2018-08-03]

5. General Medical Council. 2013. Good Practice in Prescribing and Managing Medicines and Devices URL: https://www. gmc-uk.org/Prescribing guidance.pdf 59055247.pdf [accessed 2018-08-10]

6. Martin D, Millson D, Avery A, Smart S. The King's Fund. 2011. The Quality of GP Prescribing URL: https://www. kingsfund.org.uk/sites/files/kf/field/field document/quality-gp-prescribing-gp-inquiry-research-paper-mar11.pdf [accessed 2019-01-26]

7. National Prescribing Centre. Pharmaceutical Services Negotiating Committee (PSNC). Liverpool: National Prescribing Centre; 2008 Sep. Dispensing with Repeats: A Practical Guide to Repeat Dispensing. Second Edition URL: http://archive. psnc.org.uk/data/files/repeat dispensing/npcdispensing with repeats.pdf [accessed 2019-02-02]

8. Boyd S, Moore L, Gilchrist M, Costelloe C, Castro-Sánchez E, Franklin B, et al. Obtaining antibiotics online from within the UK: a cross-sectional study. J Antimicrob Chemother 2017 May 1;72(5):1521-1528 [FREE Full text] [doi: 10.1093/jac/dkx003] [Medline: 28333179]

9. Alwon B, Solomon G, Hussain F, Wright D. A detailed analysis of online pharmacy characteristics to inform safe usage by patients. Int J Clin Pharm 2015 Feb;37(1):148-158. [doi: 10.1007/s11096-014-0056-1] [Medline: 25564180]

10. General Pharmaceutical Council. 2018 Jun. Discussion Paper on Making Sure Patients and the Public Obtain Medicines and Other Pharmacy Services Safely Online URL: https://www.pharmacyregulation.org/sites/default/files/document/ discussion paper on safe online pharmacy june 2018 0.pdf [accessed 2019-02-07]

11. Care Quality Commission. 2018. The State of Care in Independent Online Primary Health Services URL: https://www. cqc.org.uk/publications/major-report/state-care-independent-online-primary-health-services [accessed 2019-02-07]

12. Lloyds Pharmacy. NHS Experienced Clinicians | LloydsPharmacy. 2019. Chlamydia Treatment URL: https://onlinedoctor. lloydspharmacy.com/uk/sti-treatments/chlamydia-treatment [accessed 2019-03-04]

13. Superdrug. Superdrug Online Doctor. 2019. Chlamydia Treatment URL: https://onlinedoctor.superdrug.com/ chlamydia-treatment.html [accessed 2019-01-25]

14. Tideman R, Chen M, Pitts M, Ginige S, Slaney M, Fairley C. A randomised controlled trial comparing computer-assisted with face-to-face sexual history taking in a clinical setting. Sex Transm Infect 2007 Feb;83(1):52-56 [FREE Full text] [doi: 10.1136/sti.2006.020776] [Medline: 17098771]

15. Kurth AE, Martin DP, Golden MR, Weiss NS, Heagerty PJ, Spielberg F, et al. A comparison between audio computer-assisted self-interviews and clinician interviews for obtaining the sexual history. Sex Transm Dis 2004 Dec;31(12):719-726. [doi: 10.1097/01.olq.0000145855.36181.13] [Medline: 15608586 ]

16. Richens J, Copas A, Sadiq ST, Kingori P, McCarthy O, Jones V, et al. A randomised controlled trial of computer-assisted interviewing in sexual health clinics. Sex Transm Infect 2010 Aug;86(4):310-314. [doi: 10.1136/sti.2010.043422] [Medline: 20551234]

17. Ghanem KG, Hutton HE, Zenilman JM, Zimba R, Erbelding EJ. Audio computer assisted self interview and face to face interview modes in assessing response bias among STD clinic patients. Sex Transm Infect 2005 Oct;81(5):421-425 [FREE Full text] [doi: 10.1136/sti.2004.013193] [Medline: 16199744]

18. NHS England. NHS Long term plan. 2019. URL: https://www.longtermplan.nhs.uk/ [accessed 2019-01-25]

19. Wilson E, Leyrat C, Baraitser P, Free C. Does internet-accessed STI (e-STI) testing increase testing uptake for chlamydia and other STIs among a young population who have never tested? Secondary analyses of data from a randomised controlled trial. Sex Transm Infect 2019 Dec;95(8):569-574 [FREE Full text] [doi: 10.1136/sextrans-2019-053992] [Medline: $\underline{31175210]}$

20. Public Health England. The Government of UK. 2018 Nov 28. National Chlamydia Screening Programme Standards. Seventh Edition URL: https://www.gov.uk/government/publications/ncsp-standards [accessed 2019-01-25]

21. British Association for Sexual Health and HIV (BASHH). 2019. Standards for the Management of Sexually Transmitted Infections (STIs) URL: https://www.bashh.org/about-bashh/publications/standards-for-the-management-of-stis/ [accessed 2019-05-01]

22. Public Health England. The Government of UK. 2018. NCSP 2017 Audit Report. Audit of Standards: Turnaround Times, Partner Notification and Re-Testing URL: https://assets.publishing.service.gov.uk/government/uploads/system/uploads/ attachment data/file/713332/NCSP 2017 audit report.pdf [accessed 2019-05-01]

23. Estcourt CS, Gibbs J, Sutcliffe LJ, Gkatzidou V, Tickle L, Hone K, et al. The eSexual Health Clinic system for management, prevention, and control of sexually transmitted infections: exploratory studies in people testing for Chlamydia trachomatis. 
Lancet Public Health 2017 Apr;2(4):e182-e190 [FREE Full text] [doi: 10.1016/S2468-2667(17)30034-8] [Medline: 29253450]

24. Faculty of Sexual and Reproductive Healthcare (FSRH), British Association for Sexual Health and HIV (BASHH). The Faculty of Sexual and Reproductive Healthcare. London, UK: Joint BASHH/FSRH Standard; 2019 Jan. Standards for Online and Remote Providers of Sexual and Reproductive Health Services URL: https://www.fsrh.org/standards-and-guidance/ documents/fsrhbashh-standards-for-online-and-remote-providers-of-sexual/ [accessed 2019-05-01]

25. General Medical Council. 2018. Remote Consultations URL: https://www.gmc-uk.org/ethical-guidance/ethical-hub/ remote-consultations [accessed 2019-01-06]

26. Williams D. Medication errors. J R Coll Physicians Edinb 2007;37(4):343-347 [FREE Full text]

27. Department of Health and Social Care, Public Health England. The Government of UK. 2018. Integrated Sexual Health Services: A Suggested National Service Specification URL: https://assets.publishing.service.gov.uk/government/uploads/ system/uploads/attachment data/file/731140/integrated-sexual-health-services-specification.pdf [accessed 2019-07-15]

28. Greaves A, Lonsdale S, Whinney S, Hood E, Mossop H, Olowokure B. University undergraduates' knowledge of chlamydia screening services and chlamydia infection following the introduction of a National Chlamydia Screening Programme. Eur J Contracept Reprod Health Care 2009 Feb;14(1):61-68. [doi: 10.1080/13625180802434884] [Medline: 19241303]

29. Chaudhary R, Heffernan CM, Illsley AL, Jarvie LK, Lattimer C, Nwuba AE, et al. Opportunistic screening for Chlamydia: a pilot study into male perspectives on provision of Chlamydia screening in a UK university. J Public Health (Oxf) 2008 Dec;30(4):466-471. [doi: 10.1093/pubmed/fdn060] [Medline: 18653445]

30. Lorimer K, Hart GJ. Knowledge of Chlamydia trachomatis among men and women approached to participate in community-based screening, Scotland, UK. BMC Public Health 2010 Dec 30;10:794 [FREE Full text] [doi: 10.1186/1471-2458-10-794] [Medline: 21192793]

31. National Voices. 2014. Supporting Self-Management: Summarising Evidence From Systematic Reviews URL: https://www. nationalvoices.org.uk/sites/default/files/public/publications/supporting self-management.pdf [accessed 2019-07-15]

32. Turner KM, Zienkiewicz AK, Syred J, Looker KJ, de Sa J, Brady M, et al. Web-based activity within a sexual health economy: observational study. J Med Internet Res 2018 Mar 7;20(3):e74 [FREE Full text] [doi: 10.2196/jmir.8101] [Medline: $\underline{29514776}$

33. National Institute for Health and Care Excellence. 2019. Chlamydia - Uncomplicated Genital URL: https://cks.nice.org.uk/ chlamydia-uncomplicated-genital\#!topicSummary [accessed 2019-07-15]

34. Scottish Intercollegiate Guidelines Network. Management of genital Chlamydia trachomatis infection: A national clinical guideline. 2009. NHS Quality Improvement Scotland URL: https://www.sign.ac.uk/assets/sign109.pdf [accessed 2020-06-01]

\author{
Abbreviations \\ BASHH: British Association for Sexual Health and HIV \\ GMC: General Medical Council \\ NCSP: National Chlamydia Screening Programme \\ NHS: National Health Service \\ SDA: single dose of Azithromycin \\ SH: 24: Sexual Health 24 hours a day \\ STI: sexually transmitted infection
}

Edited by G Eysenbach; submitted 29.08.19; peer-reviewed by J Gibbs, SC Pan; comments to author 14.12.19; revised version received
16.01.20; accepted 24.02.20; published 17.06.20
Please cite as:
McCulloch H, Syred J, Holdsworth G, Howroyd C, Ardines E, Baraitser P
Communication Strategies Used to Obtain Clinical Histories Before Remotely Prescribing Antibiotics for Postal Treatment of
Uncomplicated Genital Chlamydia: Service Evaluation
J Med Internet Res 2020;22(6):e15970
URL: $\underline{\text { http://www.jmir.org/2020/6/e15970/ }}$
doi: $\underline{10.2196 / 15970}$
PMID: $\underline{32554379}$

(CHannah McCulloch, Jonathan Syred, Gillian Holdsworth, Chris Howroyd, Elena Ardines, Paula Baraitser. Originally published in the Journal of Medical Internet Research (http://www.jmir.org), 17.06.2020. This is an open-access article distributed under the terms of the Creative Commons Attribution License (https://creativecommons.org/licenses/by/4.0/), which permits unrestricted use, distribution, and reproduction in any medium, provided the original work, first published in the Journal of Medical Internet 
Research, is properly cited. The complete bibliographic information, a link to the original publication on http://www.jmir.org/, as well as this copyright and license information must be included. 